\title{
CONTRIBUIÇÕES ARQUEOLÓGICAS, ETNOARQUEOLÓGICAS E ETNO-HISTÓRICAS PARA O ESTUDO DOS GRUPOS TRIBAIS DO BRASIL CENTRAL: O CASO BORORO*
}

Irmhild Wiüst**

\begin{abstract}
WÜST, I. Contribuições arqueológicas, etnoarqueológicas e etno-históricas para o estudo dos grupos tribais do Brasil Central: o caso Bororo. Rev. do Museu de Arqueologia e Etnologia. S. Paulo, 2:13-26, 1992.
\end{abstract}

RESUMO: As evidências arqueológicas, etnoarqueológicas e etnohistóricas sugerem que os Índios Bororo do sudeste do Mato Grosso resultaram da fusão de grupos étnicos e culturais distintos. A ruptura com os agricultores da tradição Uru, que ocuparam anteriormente esta área, é explicada em termos de pressões internas e externas e do predomínio político de um grupo provavelmente minoritário, portador de uma nova estratégia de subsistência, padrão de assentamento e tecnologia, instaurando-se uma nova ordem social a um nível de integração regional mais amplo, dramaticamente interrompido a partir dos primeiros contatos diretos com a sociedade nacional.

UNITERMOS: Arqueologia, Etnoarqueologia, Etno-história, Indios Bororo do Mato Grosso, Brasil Central.

\section{Os grupos tribais do Brasil Central à luz da etnologia}

Diante dos interesses atuais de expansão da sociedade nacional sobre áreas indígenas, que evidenciam uma baixa densidade demo-

$\left({ }^{\star}\right)$ Este artigo representa uma sintese de alguns dos resultados referentes ao Projeto Etnoarqueológico e Arqueológico da Bacia do Rio São Lourenço, MT, que contou com o apoio financeiro da FAPESP e cujos dados foram originalmente apresentados na minha tese de Doutorado: "Continuidade e mudança - para uma interpretação dos grupos ceramistas pré-coloniais da Bacia do Rio Vermelho, Mato Grosso“. Universidade de Sào Paulo, 1990, sob a orientaçāo da Prof Dre Renate B. Viertler.

(**) Departamento de Ciências Sociais e Museu Antropológico da Universidade Federal de Goiás. gráfica e um elevado potencial de riquezas do subsolo, percebe-se uma estratégia intencional em perpetuar estereótipos, segundo os quais a configuração sócio-cultural atual dos grupos idigenas é tomada como referência de sua condição anterior ao contato. As recentes pesquisas arqueológicas etno-históricas na Amazônia (Roosevelt, 1987, 1991) e na área do Chaco (Susnik, 1972, 1978) evidenciam que, em pelo menos algumas áreas, o Brasil pré-colonial foi palco do desenvolvimento de sociedades cuja organização sócio-política pode ser caracterizada por chefias. Dentro desta perspectiva a pesquisa arqueológica no Brasil Central desempenha um papel de vital importância, sobretudo no que se refere àquelas variáveis que poderiam estar em jogo no processo da complexificação sócio-cultu- 
WOST, I. Contribuições arqueológicas, etnoarqueológicas e etno-históricas para o estudo dos grupos tribais do Brasil Central: o caso Bororo. Rev. do Museu de Arqueologia e Etnologia, S. Paulo, 2:13-26, 1992.

ral em áreas vizinhas. Na medida em que a teoria da circunscrição de Carneiro (1970) se demonstrar como modelo explanatório plausivel para o surgimento de chefias, a natureza da ocupaçāo dos interflúvios amazônicos e do Brasil Central pode conter chaves importantes para a compreensão neste processo da hierarquização entre assentamentos e da integração regional.

No contexto do desenvolvimento sóciocultural da América do Sul, os grupos tribais do Brasil Central foram tradicionalmente considerados como marginais (Steward e Faron, 1959; Steward, 1946). Esta concepção errônea foi revidada desde Nimuendajú $(1939,1946)$, uma vez que estes grupos se revelaram como portadores de complexos sistemas sociais cujos assentamentos comportaram até 1.400 indivíduos (Nimuendajú, 1939). Enquanto os primeiros autores mencionados consideram os grupos Jê, dentro de uma perspectiva evolucionista, como representantes da transição entre o estágio de caça e coleta à agricultura, Lévi-Strauss (1970) os concebe como remanescentes de agricultores empobrecidos, provenientes da floresta tropical e adaptados a meio-ambientes menos favoráveis. Devido às abordagens etnológicas, em geral desprovidas de uma profundidade temporal maior, os grapos Jê foram, assim, carregados de um estigma de anomalia em que a organização sóciopolítica estaria em contradição com o quadro tecnológico, o sistema de subsistência e o comportamento territorial. Dentro desta ótica se nega para grande parte destes grupos indigenas o conhecimento da tecnologia cerâmica, enfatizam-se os movimentos sazonais e uma elevada mobilidade espacial, além do baixo grau de permanência das aldeias base, freqüentemente atribuído ao rápido esgotamento de solos (Meggers, 1954) ou à carência de proteinas (Gross, 1975).

Turner (1979), por sua vez, explica os diferentes graus de complexificação dos grupos da Amazônia e do Brasil Central por princípios estruturais essencialmente distintos de sua organização social. Segundo este modelo as patrilinhagens exogâmicas da Amazônia favoreceriam uma integração regional e uma maior hierarquização entre comunidades locais, enquanto os sistemas segmentários Jê, nos quais prevalece uma endogamia local, não exigiria relaçōes formais entre comunidades locais o que em última conseqüência representaria um constrangimento estrutural que impediria um processo de complexificação e integração regional.

Todos estes modelos foram construídos a partir de uma situação etnográfica, já fortemente afetada pelo contato com o elemento colonizador, de modo que dificilmente poderão ser projetados para situações mais remotas. Os dados arqueológicos, até agora disponiveis para o Brasil Central, evidenciam que as sociedades ceramistas e agricultoras, estabelecidas em grandes aldeias anulares demograficamente expressivas, remontam pelo menos ao século VIII da nossa era e que em casos especificos existia uma clara hierarquização a nivel de sistemas de assentamentos e uma eventual divisāo de trabalho entre unidades domésticas (Wüst, 1990). Embora a espessura do refugo dos assentamentos raramente ultrapasse $40 \mathrm{~cm}$, indicando uma ocupação relativamente curta, os padrões distribucionais dos assentamentos indicam, em geral, apenas micro-deslocamentos que não podem ser explicados por fatores ambientais limitantes (Carneiro, 1973).

Tentaremos mostrar neste artigo, à luz dos dados etnográficos, etno-históricos e arqueológicos para uma área que compreende uma parte do tradicional território Bororo que, pelo menos neste caso especifico, existiram alguns mecanismos de organização sócio-política supra-aldeias, uma hierarquia predominantemente cerimonial entre assentamentos e uma dinâmica incorporativa própria, de modo que os grupos tribais da atualidade etnográfica podem ser considerados apenas como uma pálida imagem daquelas sociedades que ocuparam o Brasil Central em tempos anteriores ao contato.

\section{A arqueologia dos grupos ceramistas do Brasil Central - um balanço}

As pesquisas arqueológicas sistemáticas no Brasil Central, durante os seus vinte anos de existência, forneceram, a partir da prospecção de algumas centenas de sítios, um quadro cronológico e um primeiro esboço da diversidade cultural dos povos pré-coloniais no âmbito regional (Schmitz et al., 1982; Prous, 1991). 
WŨST, I. Contribuições arqueológicas, etnoarqueológicas e etno-históricas para o estudo dos grupos tribais do Brasil Central: o caso Bororo. Rev. do Museu de Arqueologia e Etmologia, S. Paulo, 2:13-26, 1992.

Embora evidências indiretas do cultivo remontem em Minas Gerais a aproximadamente 2.000 a. C. (Bird, Dias \& Carvalho, 1991), o Brasil Central não parece ter figurado como berço da domesticação de plantas. $O$ aparecimento das grandes aldeias anulares parece ocorrer de forma relativamente subita, fato que é usualmente interpretado em termos de ondas migratórias. Tanto em Minas Gerais, como no Mato Grosso, os implementos liticos lascados não parecem sofrer mudanças significativas com o advento da ceràmica ou o surgimento dos grupos agricultores, de modo que a hipótese de uma continuidade étnica parece por hora mais plausivel que aquela de um intenso processo migratório.

Os recipientes cerâmicos das tradiçōes mais antigas, tais como os das tradições Una e Aratu/Sapucaí parecem estar relacionados a um cultivo preponderante de milho e de tubérculos. A Tradição Uru, à qual se atribui uma vaga influência Amazônica, parece indicar - a partir dos recipientes cerâmicos que abrangem grandes assadores, tigelas rasas em conjunto com cântaros (Brochado, 1977) - que os seus portadores parecem ter cultivado a mandioca e a transformaram em farinha e/ou beiju. Enquanto no Estado de Goiás as tradições ceramistas Aratu/Sapucaí e Uru parecem ser contemporâneas, pelo menos a partir do século XII da nossa era, não se encontrou, até o momento, nenhum sítio da tradição Uru ao leste do rio Tocantins e sítios da tradição ceramista Aratu/Supucaí parecem estar ausentes no sudeste do Mato Grosso.

A vocação específica da arqueologia dos grupos agricultores pré-coloniais do Brasil Central nos parece residir no seu potencial de poder contribuir na compreensão de alguns dos fatores envolvidos no surgimento das grandes aldeias populosas, nos processos de transformação e nos mecanismos de manutenção destas sociedades com estruturas sociais relativamente sofisticadas, bem como dos possiveis constrangimentos exercidos sobre a expansão territorial e da complexificação sócio-cultural de grupos vizinhos.

No entanto, a maioria dos resultados arqueológicos, até agora obtidos, se limitam a meras descriçōes da cultura material, priorizando-se, sobretudo, os artefatos cerâmicos. A partir da distribuição geográfica das tradiçōes ceramistas foram estabelecidas rotas de migração e se delinearam influências culturais de caráter difusionista atribuindo-se, de um modo geral, às unidades classificatórias uma realidade sociológica. Não faltam tentativas que correlacionem tradições arqueológicas com grupos tribais especificos, sem que se disponha, na maioria dos casos, de provas consistentes sobre a continuidade cultural entre o registro arqueológico e o presente etnográfico (cf., entre outros, Schmitz et al., 1982; Dias et al., 1976), perpetuando-se, desta forma, uma visão essencialmente estática destas sociedades.

A investigação arqueológica do Brasil Central, de um modo geral, ainda impregnada por uma visão normativa da cultura, e portanto, desprovida de uma preocupação amostral a nivel de sitio e de área, contribuiu até hoje muito pouco para uma melhor compreensão da dinâmica interna e externa destes grupos pré-coloniais, inclusive dos processos relativos ao contato com a sociedade nacional. Questōes antropologicamente relevantes entre as quais podem ser destacadas: a hierarquização interna, sistemas de abastecimento em relação à capacidade de suporte e a natureza das relaçōes intra e extra-tribais (redes de troca, simbioses, padrões de guerra, etc.), exigem necessariamente estudos de sistemas de assentamentos, o estabelecimento de parâmetros demográficos, a determinação das diversas formas de apropriação territorial ao longo do ciclo anual, e, nāo por último, a investigação da variabilidade da cultura material a nivel de unidades familiares e/ou domésticas. Dentro desta perspectiva o meio-ambiente físico deixa de constituir um mero cenário sem potencial interpretativo, de modo que se possam detectar possíveis acessos diferenciados aos recursos, indicadores primordiais da estratificação social interna e das hierarquias entre assentamentos.

\section{A ocupaçāo pré-colonial do sudeste do Mato Grosso: dados etno-históricos e etnoarqueológicos}

Os Índios Bororo figuram entre os poucos grupos tribais do Brasil Central para os quais se dispōe de uma extensa literatura etnológica 
WOST, I. Contribuiçōes arqueológicas, etnoarqueológicas e etno-históricas para o estudo dos grupos tribais do Brasil Central: o caso Bororo. Rev. do Museu de Arqueologia e Etnologia, S. Paulo, 2:13-26, 1992.

que, de um modo geral, carece de uma profundidade temporal. Primeiras tentativas de compreender, a partir do corpo mítico e da tradição oral, processos da formação sóciocultural podem ser encontradas, entre outros, em Viertler $(1982,1986,1987)$. Por outro lado, carecemos, sobretudo, de pesquisas sistemáticas que permitam estabelecer uma relação entre a organização social e a sua cristalização material não perecivel, fato que dificulta a elaboração de hipóteses arqueologicamente testáveis.

A origem mais remota dos Bororo é até hoje pouco esclarecida. Tonelli (1927), assumindo uma posição difusionista extremada e pouco fundamentada supõe que seriam procedentes do alto rio Negro e Orinoco, e que após a sua passagem pelos rios Madeira, Mamoré e Guaporé teriam passado por algum tempo entre os Capacura da Bolivia até chegar ao seu habitat atual. Por outro lado, Zerries (1953, 1976) e Crocker (1969), baseando-se em aspectos mitológicos, suspeitam de uma origem pluri-cultural. Enquanto o primeiro autor atribui o surgimento do sistema dual à fusão de dois grupos culturais distintos (caçadores/coletores e agricultores), Crocker (1969) aponta para a existência de possiveis grupos locais espacialmente distintos que parecem corresponder a grupos proto-clânicos posteriormente integrados.

Tendo em vista que a maioria dos grupos amazônicos, etnograficamente documentados, carece de uma estrutura social segmentária, reforçaria a idéia de um mecanismo adaptativo próprio dos grupos do Brasil Central, que eventualmente antecederia ao estabelecimento das grandes aldeias anulares dos agricultores. Tanto esta especificidade da organização social, quanto a configuração espacial dos seus assentamentos parecem constituir o argumento básico para refutar a sua suposta origem alóctone.

As fontes etno-históricas e etnográficas indicam que os Bororo Orientais ocupavam em meados do século XIX uma área que se estendia em sentido leste-oeste desde o Estado de Goiás (cabeceiras do rio Claro e Caiapozinho) até o rio Paraguai (entre o Porto de Descalvado até as proximidades de Corumbá) e em direção norte-sul desde os afluentes da margem esquerda do rio das Mortes até o rio Taquari (Albisetti \& Venturelli, 1962: mapa;
Colbacchini \& Albisetti, 1942:29). A expansão dos Bororo para a margem direita do rio Araguaia, no entanto, parece ter-se dado apenas ao final da era das monçōes com o extermínio dos Kayapó do Sul na segunda metade do século XVIII (Caldas, 1887:18), iniciandose um refluxo dos Bororo para o Mato Grosso no final do século passado. No início do século XX o território Bororo já estava consideravelmente reduzido, tendo como limite leste o rio das Garças, a oeste o rio Cuiabá, ao norte o rio das Mortes, e ao sul o baixo rio São Lourenço e rio Itiquira (Colbacchini \& Albisetti, 1942:29).

Atualmente os Bororo estão confinados em 4 Reservas situadas nos afluentes da margem direita do rio das Mortes, no baixo curso do rio Tadarimana e no médio e baixo rio São Lourenço. Esta população conta hoje com um total de 708 indios que moram em 7 aldeias principais (Meruri, Sangradouro, Garças, Tadarimana, Piebaga, Córrego Grande e Perigara), sendo que mais da metade encontra-se na área das Missōes Salesianas (Novaes \& Grupioni, 1986).

Nas fontes etno-históricas o nome Bororo aparece apenas a partir de 1727 (Carvalho, 1937:93), sendo estes anteriormente chamados de Porrudos, Coxiponês ou Araripoconês. Uma observação de Caldas (1887:18) deixa transparecer que haveria uma certa diferença entre estas denominações, e que os Bororo seriam compostos, além dos antigos Porrudos, talvez por outros contingentes étnicos. Da mesma forma Sá (1975:10) distingue na sua listagem dos grupos indigenas do Mato Grosso do século XVIII entre os Porrudos e os Bororo.

As referências etno-históricas mais remotas sobre a ocupação indigena da bacia do rio Vermelho somente são disponiveis para meados do século XIX, quando os Bororo desta área são mencionados no contexto das tentativas de pacificação das aldeias do rio São Lourenço. O contato direto dos Bororo do rio Vermelho, também chamados de "Bororo Livres", todavia, se dá apenas no final do século XIX por ocasião da construção da linha telegráfica de Goiás a Cuiabá (Rondon, 1949).

Sobre a classificação da língua Bororo, permanecem ainda algumas dúvidas, embora a maioria dos lingüistas a considere hoje a nivel de familia, como pertencente ao tronco Ma- 
WÜST, I. Contribuiçōes arqueológicas, etnoarqueológicas e etno-históricas para o estudo dos grupos tribais do Brasil Central: o caso Bororo. Rev. do Museu de Arqueologia e Etnologia, S. Paulo, 2:13-26, 1992.

cro-Jê (Greenberg 1987; Rodrigues, 1986:4756). Segundo Créqui-Monfort \& Rivet (1913), - Bororo pertence ao tronco Otukê, posiçāo também endossada por Viertler (1982). Loukotka (1939), apesar de verificar uma certa semelhança do Bororo com linguas Jê, detecta certos elementos lingüísticos Tupi, fato que parece se confirmar por recentes investigaçōes de Aryon Rodrigues que os considera, todavia, como relativamente recentes (comunicação pessoal, 1992). Martius (1867:209263), que teve contato com os Bororo Ocidentais (apud Ehrenreich, 1891:121- 122), os caracteriza, a partir dos aspectos físicos, de forma pejorativa como "colluvies gentium", classificando-os lingüisticamente como TupiCentral, hipótese atualmente descartada, mas que diante das recentes evidências arqueológicas, merece uma certa reavaliação.

Os únicos dados quantitativos, baseados no método léxico-estatistico de Swadesh, foram publicados para os Umotina (Schultz, 1961/62a), os quais evidenciam 52\% de cognatos com Bororo, $28 \%$ com Kayapó e $15 \%$ com Kaingang. Isto indica uma filiação genética relativamente estreita do Umotina com a língua Bororo, porém, uma separação mais remota e uma possivel origem comum, especialmente com linguas dos Jê setentrionais.

A partir da constatação de dois tipos físicos distintos entre os Bororo (Albisetti \& Venturelli, 1962:286), um predominantemente platirrino e outro leptorrino, estes autores sugerem que esta tribo teria sido formada por contingentes raciais distintos. Por outro lado, Neves et al. (1985), ao comparar 9 medidas antropométricas, por meio da análise de componentes principais, de diversos grupos lingüísticos e culturais do Brasil, demonstram que os Bororo se agrupam nitidamente, porém de forma decrescente, com os Kaingang do Paraná e Rio Grande do Sul, Aruák da fronteira com o Peru, Guarani do Paraná e Rio Grande do Sul e os Kayapó do Pará e Mato Grosso. Estes dados parecem indicar, devido aos supostos fluxos genéticos, uma possivel remota origem comum e que vão parcialmente ao encontro dos dados lingüisticos acima apontados.

A organização social Bororo caracterizase por um sistema dual exogâmico composto por oito clãs matrilineares por sua vez subdivididos em diversas linhagens hierarquica- mente ordenadas, com implicaçōes significativas no que tange à escolha dos chefes, às privacidades clânicas e à rede de redistribuição de bens de consumo e/ou prestigio (Viertler, 1991). Por sua vez, uma certa divisão de trabalho parece ter ultrapassado aquela de sexo e idade, como por exemplo, a confecção de determinados objetos de pedra (Lowie, 1946:428).

Em oposição aos outros grupos Jê, a estrutura social Bororo se cristaliza a nivel da planta de uma aldeia, de modo que a disposição das unidades residenciais matrilineares segue um padrão preestabelecido, orientada pelos pontos cardeais leste-oeste e a direção do curso d'água principal. No entanto, apesar das privacidades clânicas também serem expressas por alguns recipientes cerâmicos especificos, predominantemente exclusivos dos clās da metade Tugaregue (Wüst, 1990), o complicado sistema de cessão de direitos, de uso ou da posse temporária, nāo leva necessariamente em contextos arqueológicos a uma nítida cristalização espacial da organização social.

Segundo a tradição oral formal e informal, os Bororo se concebem como resultado de um processo confederativo de grupos locais antigamente dispersos e em conflitos constantes. $\mathrm{O}$ rol das 53 aldeias consideradas pelos Bororo atuais como privativas aos clās e cuja localização aproximada foi possivel obter a partir de mapas cognitivos, é eventualmente expressão para antigas predominâncias politicas de proto-clàs ou mesmo de grupos matrilineares "iedaga-mage", que mais tarde vêm a constituir o sistema social etnograficamente conhecido. $O$ processo da confederação destes grupos locais é atribuido ao grande herói mítico Akario Bokodore da metade Excerae que recebeu os seus poderes de Akaruiio Boroge e Baitagogo, heróis miticos da metade Tugaregue e cujos membros são concebidos como os "verdadeiros" Bororo ( Albisetti \& Colbacchini, 1969:127-138). Teriam participado neste processo também membros de grupos anteriormente considerados inimigos, tais como os Karáoe posteriormente incorporados ao clã dos Iwagudo e os Koróge ao clã dos Paiwoé (Viertler, 1976).

Em oposição a outros grupos Jê (Maybury-Lewis, 1967), os membros de uma aldeia Bororo gozavam, a partir da consolidação final do sistema social, de livre acesso a todos os 
WÜST, I. Contribuiçòes arqueológicas, etnoarqueológicas e etno-históricas para o estudo dos grupos tribais do Brasil Central: o caso Bororo. Rev. do Museu de Arqueologia e Emologia, S. Paulo, 2:13-26, 1992.

demais assentamentos, organizados segundo um mesmo princípio estrutural. A repetiçāo das denominaçōes das supostas aldeias fundadoras e a sua localização em diversas partes do território tribal sugerem que não se trata de um evento único, mas de um desdobramento de um crescente processo de integração regional que culmina e cessa com o estabelecimento da aldeia Arigao Bororo do rio Vermelho.

Embora os assentamentos Bororo figurem tradicionalmente como unidades sóciopolíticas e econômicas autônomas, as histórias de vida revelam intensas redes de relaçōes sociais envolvendo um sistema de troca de matérias primas raras, de prestigio e de mulheres, especialmente ativadas por ocasião dos funerais e de um prolongado percorrimento do território, empreendido por ocasião da iniciação dos jovens. Apesar de uma certa prática sazonal, ainda muito pouco compreendida, as aldeias base nunca são totalmente abandonadas, participando nestes "magurus" apenas segmentos de uma comunidade local. Por sua vez, o abandono de uma aldeia é predominantemente motivado por mortes repetidas ou questões de salubridade e não por conflitos internos ou escassez de recursos (Gross 1983). Prevalecem, assim, os micro-deslocamentos de modo que o nome de uma aldeia refere-se a uma certa localidade, na qual arqueologicamente podem ser encontradas, em espaços muito próximos, aldeias sucessivas, o que dificulta uma identificação temporal precisa.

A comunicação entre as aldeias estava assegurada por um grupo de jovens e Cruz (1941) menciona a existência de uma classe de guerreiros, formada por solteiros jovens. A hierarquia entre as aldeias é oriunda da presença de grandes chefes que, entre outros, garantem um desempenho ritual mais imponente, sobretudo, por ocasião dos rituais funerários nos quais participam membros de aldeias vizinhas. No entanto, o elevado fluxo populacional entre as aldeias (que em Tadarimana em 1983/4 alcançou $30 \%$ ) torna estas hierarquias relativamente instáveis de modo que nem necessariamente se cristalizam em termos da quantidade de unidades residenciais ou do tamanho de um assentamento, uma vez que os visitantes são geralmente abrigados por seus parentes clânicos, mesmo quando a sua permanência ultrapassa o ciclo ritual propriamente dito (Wüst, 1990). Adicionalmente dis- pòem-se de dados etnográficos de que em contexto histórico um único chefe, o Cadete, comandava diversas aldeias (Viertler, 1982).

$\mathrm{O}$ conjunto destes dados remete a uma sociedade distinta daquela do modelo Jê propriamente dito. Levando ainda em consideração que em áreas vizinhas existiram, ainda no primeiro século da conquista, sociedades, tais como os Orejones ao sudoeste, cuja organização sócio-política pode ser caracterizada por chefia, não se pode excluir a hipótese que alguns dos grupos proto-Bororo passaram por um semelhante processo de complexificação, principalmente na medida em que sofreram pressōes diretas ou indiretas da sociedade nacional.

Tanto as epidemias, quanto os conflitos armados que envolveram os Kayapó do Sul e Payaguả (Siqueira, 1898/99; Caldas, 1887), além da própria sociedade nacional, levaram a uma forte dizimação da população Bororo, contribuindo certamente para um nivelamento de hierarquias internas e entre aldeias. Desconhecemos ainda os seus padrōes demográficos tradicionais, uma vez que os primeiros censos se referem ao final do século XIX, quando já se encontram em pleno processo de dizimação, de modo que estes dados não podem ser projetados para um passado anterior ao contato. Uma comparação dos censos disponíveis evidencia uma redução significativa da média de pessoas por unidade residencial, sendo esta para o periodo de 1905/1919 de aproximadamente 11 habitantes, enquanto nas aldeias posteriores a 1936 atinge apenas 6 individuos (Wüst, 1990). Os 3.595 Bororo do alto e baixo São Lourenço que se apresentaram em 1888 na Colônia Tereza Cristina (Mello Rego, 1895) eram provenientes de apenas 4 aldeias, sendo que sobre a população dos habitantes das demais 30 aldeias já pacificadas as fontes etno-históricas silenciam.

Segundo Colbacchini \& Albisetti (1942) há noticias de antigas aldeias que comportaram 5 a mais anéis concêntricos de casas, e a planta de uma aldeia, provavelmente contatada por membros da comissão Rondon, evidencia 140 unidades residenciais, ordenadas em três anéis concêntricos (Rondon \& Faria, 1948). Partindo-se do parâmetro de uma, duas ou três familias nucleares por casa chegar-seia, apenas para esta aldeia, a uma população que varia de 600 e 1.800 indivíduos. 
WOST, I. Contribuiçōes arqueológicas, etnoarqueológicas e etno-históricas para o estudo dos grupos tribais do Brasil Central: o caso Bororo. Rev. do Museu de Arqueologia e Emologia, S. Paulo, 2:13-26, 1992.

\section{Os dados arqueológicos}

Apesar de uma visibilidade arqueológica parcialmente comprometida pela cobertura vegetal atual, realizaram-se prospecçōes sistemáticas em 11 áreas-pilotos, situadas ao longo do alto e meio curso do rio Vermelho, maior afluente do rio São Lourenço que desagua no rio Paraguai e de alguns dos seus interflúvios. Trata-se de uma área que é considerada como tradicional território Bororo e que foi diretamente atingida pela expansão da sociedade nacional apenas na virada deste século.

No que se refere aos assentamentos de caráter habitacional a céu aberto dos grupos ceramistas, foram pesquisados ao todo 63 sitios dos quais 34 (54\%) foram atribuidos aos portadores da tradição Uru. A partir das evidências materiais, inclusive da presença de artefatos de origem neo-brasileira, outros 23 (37\%) puderam ser identificados com antigos assentamentos dos antepassados diretos dos Bororo, enquanto apenas 6 , ou seja $9 \%$, foram atribuidos aos portadores da tradição ceramista Tupiguarani da subtradição Pintada, que, na maioria dos casos, apresenta fortes influências da tradição Uru (Wüst, 1990).

As datações absolutas e a análise comparativa dos artefatos, bem como os aspectos da implantação dos sitios e de sua localização diante da compartimentação fitogeográfica revelam na área do rio Vermelho uma nitida ruptura cultural ao redor do início do século XVIII, época em que é fundada nas proximidades da confluência do Tadarimana com o rio Vermelho a primeira aldeia Bororo (Arigao Bororo) que corresponde ao sitio arqueológico MT-SL-11.

Os grupos ceramistas da tradiçāo Uru, estabelecidos em grandes aldeias anulares, se fazem presentes pelo menos a partir do século VIII. Uma comparação multivariada dos artefatos líticos indica uma certa continuidade cultural entre o período aceràmico recente e aquele dos portadores da tradição ceramista Uru, registrando-se apenas uma maior diversificaçāo, especialmente no que se refere aos objetos de pedra polida.

A nível do quadro cerâmico verifica-se apenas a partir do século XII da nossa era a presença de grandes assadores, sendo estes ausentes nos sitios mais antigos. Enquanto os aspectos morfológicos dos demais recipientes cerâmicos parecem permanecer praticamente inalterados, este novo implemento poderia remeter a uma certa intensificação agricola, expressa por uma transformação sistemática da mandioca em farinha e/ou beiju, aumentandose, assim, o potencial da estocagem de alimentos em decorrência de aldeias cada vez mais populosas. Esta hipótese parece se confirmar por uma certa correlação estatistica entre a presença de assadores e os assentamentos maiores.

As unidades residenciais dos sítios dos portadores da tradição Uru que podem atingir um total de até 73, estão dispostas em 1 a 3 anéis concêntricos. Apesar da precariedade dos dados referentes ao tamanho das unidades residenciais destes grupos ceramistas, devido à precariedade do estado de conservação da maioria dos seus sitios, elas parecem girar ao redor de $50 \mathrm{~m}^{2}$. Supondo uma concomitância de todas as supostas unidades de habitação arqueologicamente visiveis, as aldeias maiores expressariam contingentes demográficos em torno de 1.000 individuos, enquanto as menores dificilmente suportariam mais que 200 pessoas. Em alguns destes sitios registrou-se uma deposição arqueológica na parte central que poderia corresponder à chamada "casa dos homens", hipótese reforçada pela presença seletiva dos artefatos cerâmicos em oposição àqueles das supostas unidades residenciais.

O diàmetro máximo dos sítios dos portadores da tradição Uru varia entre 110 a 380 $\mathrm{m}$ o que corresponde a uma área total de $\mathbf{8 . 2 0 7}$ a $95.504 \mathrm{~m}^{2}$. Embora o tamanho destes assentamentos apresente uma curva unimodal, verifica-se uma diferença significativa no que diz respeito à proporção entre o maior e o menor sítio dos 5 componentes cerâmicos. ${ }^{1}$ Enquanto nos componentes mais antigos esta proporção varia de 1:2 e 1:3, no componente mais recente esta pode atingir 1:7. Estas diferenças parecem remeter a uma crescente hierarquização entre os assentamentos que parece estar diretamente relacionada a diferenças demográficas significativas.

(1) A partir de uma análise multivariada dos atributos cerâmicos estabeleceram-se para a tradição Uru cinco componentes que parecem corresponder parcialmente nào apenas a niveis temporais distintos, mas que expressam, sobretudo, assentamentos de comunidades especificas. 
WÜST, I. Contribuiçòes arqueológicas, etnoarqueológicas e etno-históricas para o estudo dos grupos tribais do Brasil Central: o caso Bororo. Rev. do Museu de Arqueologia e Emologia, S. Paulo, 2:13-26, 1992.

Por outro lado, constatou-se uma correlação estatística entre o tamanho dos sitios e a ocorrência de material cerâmico de natureza "intrusiva", o que pode ser interpretado em termos de um maior fluxo de informação e/ou contato direto com sociedades culturalmente distintas nos sitios de dimensōes maiores, com possiveis implicaçòes para uma hierarquização a nivel de sistemas de assentamentos.

Um dado adicional para uma certa diferenciação sócio-cultural interna é fornecido pela distribuição espacial heterogênea de certos implementos cerâmicos especificamente constatada no sítio MT-RN-32. Aqui ocorrem, de forma alternada e quase simétrica, conjuntos de unidades residenciais com presença $e$ ausência de assadores que parecem indicar atividades relacionadas à transformação da mandioca. Poder-se-ia, portanto, sugerir que, pelo menos neste sítio, a divisào de trabalho estava regida por um mecanismo que ultrapassa aquele de sexo e idade e que existia uma alocação diferenciada da força de trabalho na produção de um dos elementos básicos da subsistência (Wüst, 1990).

Ao longo do processo da ocupação destes grupos ceramistas, verifica-se que a distribuição espacial inicialmente dispersa dos assentamentos tende para uma de caráter linear, figurando os solos mais férteis das amplas matas ciliares ao longo dos maiores cursos d'água um crescente atrativo. Embora ainda seja dificil precisar a concomitância parcial e a duração da ocupação pelos portadores dos respectivos componentes ceràmicos da tradição Uru, as médias do espaçamento entre os sítios variam nos componentes mais antigos entre 9,3 e 6,4 km, enquanto nos mais recentes atingem apenas entre 3,3 e 1,8 $\mathrm{km}$. Uma maior diversidade a nivel de cultura material e uma crescente restrição geográfica dos sitios, especialmente daqueles dos componentes mais recentes, sugerem não apenas a presença de grupos locais culturalmente distintos, bem como um aumento das tensōes demográficas, sejam internas ou externas. Esta idéia é reforçada pela ocupação do topo de um dos morros testemunhos (morro dos Araras) de dificilimo acesso, o que remete a uma evidente conotação defensiva por portadores ceramistas minoritários. Um destes sitios aqui localizados, datado em $1360 \pm 60$ [Beta-27432] indica que a área do rio Vermelho sofreu, mesmo em pe- riodo anterior a possiveis contatos indiretos com o colonizador, uma considerável pressão demográfica.

Desta forma, os dados arqueológicos evidenciam que, em um periodo anterior à ocupação por portadores da tradição ceramista Bororo, a área do rio Vermelho foi cenário de grupos ceramistas agricultores, cuja organização social provavelmente já era regida por um sistema segmentário, ocasionalmente expressa por uma divisão de trabalho a nivel de unidades domésticas e que finalmente valorizava extensas redes de relações extra-culturais.

Aqueles assentamentos que puderam ser identificados, a partir de uma continuidade cultural entre os artefatos cerâmicos e liticos e o padrão de assentamento, com antigas aldeias dos Bororo etnográficos, apresentam, na sua maioria, evidências materiais de contato com a sociedade nacional, revelando uma profundidade temporal relativamente reduzida. $\mathrm{O}$ sitio mais antigo, e que foi considerado por nossos informantes como a aldeia "mãe" da área do rio Vermelho, chamada de Arigao Bororo, foi datado em $1720 \pm 70 \mathrm{~d}$. C. [Beta27427]. Trata-se de uma aldeia que, segundo a mitologia, coincidiria com a localidade em que o chefe Akarúio Bokodori teria novamente chamado todos os Bororo (Albisetti \& Venturelli, 1969). Após um aumento demográfico considerável ter-se-ia iniciado a partir daqui um processo de dispersão em direção leste, oeste e norte, dando origem a sete novas aldeias das quais algumas sobreviveram até os primeiros contatos com a sociedade nacional no inicio do século XX.

Neste sitio (MT-SL-11) verificou-se arqueologicamente uma associação estratigráfica da tradição Uru com aquela etnograficamente documentada para os Bororo. A presença destas duas tradiçōes cerâmicas ocorre ainda em um segundo sítio arqueológico pré-contato (MT-SL-47), situado na localidade etnohistoricamente conhecida por Aroejare. No entanto, no sítio MT-RN-36, no qual já ocorrem alguns artefatos de origem neo-brasileira, verifica-se que os fragmentos ceràmicos da tradição Uru atingem apenas $0.07 \%$ do total do material. Adicionalmente, registra-se ainda em cinco antigos assentamentos Bororo pré e pós-contato (MT-RN-12, MT-RN-15, MTRN-46, MT-RN-47 e MT-SL-04 A), e que parecem corresponder a uma única ocupação, a 
WUUST, I. Contribuiçōes arqueológicas, etnoarqueológicas e etno-históricas para o estudo dos grupos tribais do Brasil Central: o caso Bororo. Rev. do Museu de Arqueologia e Etnologia, S. Paulo, 2:13-26, 1992.

presença da cerâmica da tradição Tupiguarani da subtradiçāo pintada, podendo atingir entre 0,49 e $12,46 \%$ do total do material. Por outro lado, um percentual reduzido da cerâmica morfologicamente Bororo, apresenta uma certa influência da tradição ceramista Tupiguarani e vice-versa. Estes dados poderiam elucidar a afirmação de Lévi-Strauss (1955:217), até agora pouco compreendida: "Cosa curiosa äntaño la alferiaria bororo parece haber sido decorada, pero quizas una prohibición religiosa relativamente reciente eliminó esta tecnica."

Tendo em vista que todas as três tradiçōes ceramistas apresentam carateristicas tecnológicas, morfológicas e decorativas essencialmente distintas, a sua separaçāo foi facilitada, sendo que uma análise multifatorial dos atributos ceràmicos a nivel dos sitios resultou na ocupação de espaços gráficos claramente distintos. Apenas os artefatos ceràmicos de um dos sitios, localizado no topo do Morro das Araras (MT-SL-51) apresenta uma certa posiçāo intermediária entre a tradição Uru e Bororo o que poder-se-ia interpretar eventualmente em termos de um processo mais remoto de contatos entre portadores de ambas estas tradiçōes em um periodo que recua pelo menos ao século XIV da nossa era.

As aldeias tradicionais Bororo anteriores ao contato com a sociedade nacional situamse sobre o primeiro ou segundo terraço fluvial de rios navegáveis onde prevalecem amplas matas ciliares com solos de elevada fertilidade natural. Estas aldeias seguem um padrão distribucional linear cujo espaçamento varia no inicio da primeira metade do século $\mathrm{XX}$ entre 14 e $35 \mathrm{~km}$, exibindo uma média de $20 \mathrm{~km}$. Tendo em vista que a subsistència tradicional deste grupo indigena estava baseada tanto na agricultura quanto na caça $e$ coleta, pode-se estimar um raio do territórioaldeia de aproximadamente $10 \mathrm{~km}$, o que indica, diante dos dados acima expostos, um padrão maduro que impediria uma cisào subseqüente sob prejuizo de condiçōes ambientais igualmente favoráveis.

A partir do contato direto e continuo ao redor dos anos 30 do nosso século ocorrem, no último refúgio dos "Bororo Livres" na bacia do Rio Vermelho, mudanças significativas no que se refere ao padrão de estabelecimento e à ocupação do seu tradicional território tribal. Fundaram-se pequenas aldeias e acampa- mentos em áreas de baixa fertilidade natural, longe dos rios piscosos, as vezes em áreas muito acidentadas. Esta alteração significativa do padrão tradicional se deu em decorrência das pressōes da sociedade nacional, seja por ocasião da construção de linhas telegráficas, seja da instalação de fazendas agro-pastoris, empreendimentos nos quais os Bororo foram empregados como mão de obra em troca de alguns bens industrializados. Apenas nos anos 50 quando se demarcaram ou delimitaram algumas reservas, verifica-se um certo refluxo dos Bororo restantes para suas áreas tradicionais, das quais duas (Jarudore e Pobojare) atualmente já desapareceram, sofrendo as demais constantes ameaças de invasão.

Como grande parte dos registros etnográficos remonta a um periodo de elevada instabilidade e decadência cultural (Colbacchini \& Albisetti, 1942; Baldus, 1979) - em um momento em que a organização social e o sistema de abastecimento tradicional ja estavam fortemente afetados pela perda sistemática das àreas mais propicias para uma agricultura cuja base estava calcada no milho - os Bororo foram freqüentemente rotulados na literatura como caçadores/coletores semi-nômades, praticando uma agricultura incipiente. Esta imagem de um indio que "nem sabe plantar e que vaguea apenas pelo território" é perpetuada até hoje, especialmente pela população nacional diretamente envolvente, que a manipula ideologicamente para justificar a ocupação ilegal das terras (Wüst, notas de campo 1983/4).

\section{Discussão e perspectivas para a pesquisa arqueológica no Brasil Central}

Diante da pouca profundidade temporal (de aproximadamente 250 anos) daqueles grupos ceramistas na área do rio Vermelho, identificados como os antepassados diretos dos Bororo etnográficos, podem ser levantadas as seguintes hipóteses: a) a ruptura cultural arqueologicamente apreensivel é resultado de uma invasão da área por grupos culturalmente distintos; b) os grupos locais anteriores teriam substituido a confecção ceramista própria por uma ampla rede de bens importados; c) os Bororo seriam o resultado de um processo de 
WŨST, I. Contribuiçōes arqueológicas, etnoarqueológicas e etno-históricas para o estudo dos grupos tribais do Brasil Central: o caso Bororo. Rev. do Museu de Arqueologia e Etnologia, S. Paulo, 2:13-26, 1992.

fusāo de grupos culturalmente distintos, impondo-se aos antigos ocupantes da área novos padrões culturais e estéticos, entre os quais, a confecção de recipientes cerâmicos, segundo o modelo do grupo politicamente dominante.

a) Embora em um contexto de ruptura cultural o fenômeno da migração não possa ser desprezado em termos de um modelo viável, a sua confirmação exige a localização da área de origem, bem como uma compreensão dos mecanismos atuantes, tanto na área de imigração, quanto da emigração (Anthony, 1990). Enquanto a cultura material pode ser um primeiro indicador para tal processo, a sua comprovação exige necessariamente dados antropométricos.

No caso sob consideração carecemos ainda de investigações arqueológicas sistemáticas em todas as áreas adjacentes ao oeste, norte e sul do último reduto do tradicional território Bororo. Tendo em vista que as pressões demográficas advindas da área do Chaco em direção leste e da Amazônia em direção sul, parecem se acentuar a partir da conquista, e de que a tradição ceramista Bororo é aparentemente alheia ao Brasil Central em um período anterior ao século XVIII, não se pode excluir a possibilidade de um certo movimento migratório de portadores desta tradição ceramista. No entanto, apenas futuras pesquisas arqueológicas em áreas adjacentes poderão responder até que ponto o sistema sócio-cultural Bororo já existia em sua forma plena em uma outra área ou se este se formou apenas em tempo relativamente recente, hipótese que por hora parece ser a mais plausivel.

b) As evidências arqueológicas nos antigos assentamentos Bororo, tais como restos da manufatura cerâmica e o seu descarte intencional, bem como o emprego de temperos localmente disponiveis, confirmam uma produção ceramista local, de modo que o elevado grau de homogeneidade da cerâmica Bororo sobre uma extensa área geográfica deve ser compreendido em termos de uma ampla rede de fluxos de informação e de contingentes demográficos e não segundo o modelo Xinguano em que atualmente apenas um único grupo é responsável pela fabricação e distribuição de artefatos cerâmicos.

c) É evidente que o corpo mítico de uma sociedade não pode ser tratado em termos dos nossos documentos históricos, podendo no en- tanto conter elementos que, por meio de relatos de supostas origens, venham a reforçar a identidade étnica. Diante dos dados arqueológicos da bacia do Rio Vermelho, parece-nos que algumas das passagens contidas na mitologia Bororo, não podem ser consideradas como meras construçōes do imaginário, mas que retratam, de forma às vezes metafórica, um processo sócio-político intimamente relacionado a sua sobrevivência física e cultural.

Por sua vez, os dados etno-históricos, acima delineados, parecem remeter também, pelo menos para os primeiros anos do contato direto, a uma certa pluralidade cultural na área do tradicional território tribal Bororo. A datação relativamente recente da aldeia Arigao Bororo, considerada pelos Bororo como a primeira da área do rio Vermelho e que recua apenas ao início do século XVIII, bem como a natureza intra-componencial (tradição ceramista Uru, Tupiguarani e Bororo) de alguns dos antigos assentamentos Bororo, seguida por uma rápida homogeneização da cultura material em nivel regional, parecem remeter a um processo de fusão de grupos culturalmente distintos.

Tendo em vista que após o aparecimento da cerâmica Bororo a tradição ceramista Uru aparentemente desaparece, permanecendo, todavia, de forma minoritária alguns elementos da tradição ceramista Tupiguarani, coloca-se um problema interessante no que se refere à relação entre cultura material, etnia e processos sócio-culturais.

Dificilmente agricultores, como os portadores da tradição Uru, tão bem estabelecidos em uma área, cederiam o seu espaço ocupado por quase um milênio, a um suposto grupo invasor, e dificilmente todos estes grupos locais, relativamente populosos, teriam sido eliminados pelos ceramistas da tradição ceramista Bororo. A hipótese de que os habitantes das aldeias da tradição Uru representam um dos grupos que foram absorvidos por um sistema social mais amplo, parece ser mais plausivel. Resta, no entanto, indagar os motivos que poderiam tê-los levado a aceitarem uma imposição de padrões culturais e estilisticos de um eventual grupo minoritário. Por um lado as pressões de natureza indireta, exercidas pela sociedade nacional desde o século XVI, não podem ser desprezadas como variável atuante neste processo. Mas por outro lado, estamos 
WUST, 1. Contribuiçòes arqueológicas, etnoarqueológicas e etno-históricas para o estudo dos grupos tribais do Brasil Central: o caso Bororo. Rev. do Museu de Arqueologia e Etnologia, S. Paulo, 2:13-26, 1992.

inclinados a supor adicionalmente motivos de natureza essencialmente interna relacionados ao sistema de subsistência, bem como externa, expressa pela crescente pressão exercida por outros grupos culturalmente distintos.

Uma vez que não ocorre uma correspondência necessária entre grupos étnicos e o repertório da cultura material (Hodder, 1982), os dados empiricos sugerem uma situação para a qual o modelo de Hantmann \& Plog (1982) parece ser o mais plausivel. Segundo estes autores, a permanência ou a alteração de estilos podem figurar como simbolos na manutenção de status e de alianças politicas. No caso de se confirmar, por meio de outros dados independentes, uma certa continuidade étnica dos grupos agricultores anteriores (portadores da tradição ceramista Uru), estariamos, portanto, diante de uma situação em que uma homogeneização a nivel da cultura material seria expressão de um elevado grau de cooperação e não de competição entre grupos culturalmente distintos (Hodder, 1979), sobretudo em uma sociedade de natureza segmentária, a nivel de assentamento apenas parcialmente endogâmica e na qual, como no caso Bororo, a cerâmica participa de forma ativa nas representaçōes clânicas e, assim, na construção de sua identidade grupal.

Tendo em vista que em circunstâncias semelhantes outros grupos do Brasil Central reagiram de forma oposta, o caso Bororo sugere que certas condiçōes estruturais propicias favoreciam, em vez da dispersão dos assentamentos e de conflitos intra e/ou extra-comunitários, um processo de simbiose.

Embora o surgimento da elaborada estrutura social Bororo pareça ter ocorrido em um periodo relativamente recente, os dados arqueológicos apontam para uma considerável profundidade temporal das grandes aldeias anulares para cujos ocupantes se pode supor uma organização social elaborada que, pelo menos em alguns casos especificos, parece exceder o nivel de uma sociedade igualitária. Desta forma, $r$ motivo do surgimento das grandes aldeias Jê não pode ser procurado nos contatos diretos ou indiretos com a sociedade nacional, hipótese alternativa levantada por Gross (1979).

Poder-se-ia sugerir, portanto, à luz dos dados etnográficos, etno-históricos e arqueológicos que os Bororo atuais seriam o resul- tado de uma processo de incorporação de grupos étnicos e culturais distintos e que esta sociedade indigena, sob sua forma etnograficamente conhecida, conta com uma profundidade temporal relativamente limitada.

Diante das lentas transformaçōes dos sistemas sócio-culturais, os rigidos esquemas classificatórios, de cunho evolucionista, se mostram impotentes e insatisfatórios. Dentro desta perspectiva a pesquisa arqueológica dos grupos ceramistas do Brasil Central oferece um potencial significativo, na medida em que estas sociedades parecem situar-se ao longo de um continuum entre uma organização tribal $e$ a de chefias emergentes.

No entanto, é evidente que uma análise dos fatores atuantes nos processos sócio-culturais destas sociedades exige não apenas uma investigação de natureza interdisciplinar, como também uma mudança substancial na abordagem teórico-metodológica. Questōes de natureza antropologicamente relevantes poderão ser formuladas especialmente a partir da compreensão dos padrōes e sistemas de assentamento e da organização espacial intra-sitio, de modo que fatores relativos a aspectos demográficos, apropriações territoriais, hierarquias, modo de produção, redes intra e extra-comunitárias, bem como aspectos ideológicos envolvidos na manutenção, reprodução e transformação de sua condição de vida, possam figurar como variáveis chaves na reconstrução do passado.

Apesar da natureza ainda essencialmente exploratória dos dados aqui apresentados, eles evidenciam a importância de se investigar até que ponto ocorreram em outros contextos do Brasil Central processos simbióticos semelhantes. Torna-se também cada vez mais claro que as sociedades pré-coloniais do Brasil Central e as da Amazônia não poderão ser investigadas de forma isolada e que as questōes relativas à natureza dos constrangimentos e contatos culturais representam uma das chaves no entendimento das formas sócio-politicas emergentes em ambas estas áreas.

Finalizando, pode-se sugerir uma intensificação de pesquisas que possam estabelecer continuidades ou rupturas entre o registro arqueológico e etnológico por meio de um uso sistemático das fontes históricas primárias e da investigação etnoarqueológica. Dentro desta perspectiva questões relativas à cristaliza- 
WÜST, I. Contribuiçōes arqueológicas, etnoarqueológicas e etno-históricas para o estudo dos grupos tribais do Brasil Central: o caso Bororo. Rev. do Museu de Arqueologia e Etnologia, S. Paulo, 2:13-26, 1992.

çāo material da hierarquização a nivel regional e de assentamento, das estruturas sociais especificas, dos possiveis acessos diferenciados aos recursos, bem como da natureza da divisão de trabalho, assumem uma importância fundamental. Assim, a arqueologia nāo apenas contribuirá para uma melhor compreensão no que tange à natureza e à dinâmica destas sociedades pré-coloniais e de seus pos- siveis constrangimentos exercidos sobre outras áreas, bem como dos impactos causados pelo contato com a sociedade nacional, mas terá implicaçōes de cunho político no procedimento da demarcação de suas terras, geralmente alicerçado no conceito "tribo" demasiadamente estático e que expressa, em primeiro plano, uma relação entre conquistadores e conquistados.

WÜST, I. Archaeological, ethnoarchaeological and ethnohistorical contributions to the study of tribal groups in Central Brazil: the Bororo case. Rev. do Museu de Arqueologia e Etnologia. S. Paulo, 2:13-26, 1992.

ABSTRACT: Archaeological, ethnoarchaeological and ethnohistoric evidence suggest that the Bororo Indians of the southeast of Mato Grosso resulted from the fusion of distinct cultural and ethnic groups. The cultural rupture with the prior agriculturalists of Uru tradition in the area is explained in terms of internal and external pressures and political predominance of an incoming minority bearing new subsistence strategies, settlement pattern, and technology fostering a social order on a higher level of regional integration, dramatically interrupted in consequence of the first direct contacts with national society.

UNITERMS: Archaeology, Ethnoarchaeology, Ethnohistory, Bororo Indians of Mato Grosso, Central Brazil.

\section{Referências bibliográficas}

ALBISETTI, C. \& A. J. VENTURELLI Enciclopédia Bororo, Volume I. Museu Regional Dom Bosco. Campo Grande, 1962

_. Enciclopédia Bororo, Volume II. Museu Regional Dom Bosco. Campo Grande, 1969.

ANTHONY, D. W. Migration in Archaeology: the baby and the bathwater. American Anthropologist 92:895-914, 1990.

BALDUS, H. A posição social da mulher entre os Bororo Orientais. Ensaios de Emologia Brasileira. Brasiliana 101. Companhia Editora Nacional, São Paulo, 1979: 60-91.

BIRD, Mck. R. O. F. DIAS Jr. \& E. T. CARVALHO Subsidios para a arqueobotânica no Brasil: o milho antigo em cavernas de Minas Gerais. Revista de Arqueologia 6:15-32. Sociedade de Arqueologia Brasileira, 1991

BROCHADO, J. P. Alimentação na floresta tropical. Instituto de Filosofia e Ciências Humanas 2. Universidade Federal do Rio Grande do Sul, 1977.
CALDAS, J. A. Memória Histórica sobre os Indígenas da Província de Matto-Grosso. Polytechnica de Moraes \& Filho (eds.). Rio de Janeiro, 1887.

CARNEIRO, R. A theory of the origin of state. Science 169:733-738, 1970.

_. Introduction to slash-and-burn cultivation among the Kuikuru and its implications for cultural development in the Amazon Basin. D. Gross (ed.), Peoples and Cultures of Native South America. The Natural History Press. Doubleday \& Co. Inc. New York, 1973: 96-123.

CARVALHO, S. Resumo do relato de Sá Carvalho sobre a expediçāo de Atônio Pires de Campos em 1718, O Estado de São Paulo, 1937.

COLBACCHINI, A. \& C. ALBISETTI Os Boróros Ocidentais. Orarimugodoge do Planalto Oriental de Mato Grosso. Companhia Editora Nacional, Sāo Paulo, 1942.

CROCKER, C. J. Reciprocity and hierarchy among the Eastem Bororo. Man 4 (1):44-58, 1969. 
WÜST, I. Contribuiçōes arqueológicas, etnoarqueológicas e etno-históricas para o estudo dos grupos tribais do Brasil Central: o caso Bororo. Rev. do Museu de Arqueologia e Etnologia, S. Paulo, 2:13-26, 1992.

CĩUZ, M. A arte militar entre os Bororos de outrora. Revista do Instituto Histórico e Geográfico Brasileiro, Rio de Janeiro, 175: 169-182, 1940.

DIAS, O. Jr., E. CARVALHO \& L. CHEUICHE Pesquisas arqueológicas em Minas Gerais (Brasil): $O$ Propevale (Programa de pesquisas no vale do São Francisco). Actes du XLIIe Congrès International des Américanistes, Paris, IX-A: 13-34, 1979.

EHRENREICH, P. Die Einteilung und Verbreitung der Vöelkerstäemme Brasiliens nach dem gegenwaertigen Stand unserer Kenntnisse. Petermanns Mitteilungen 37:81-91; 114-124, 1891.

GREENBERG, J. H. Language in the Americas. Stanford University Press, 1987.

GROSS, D. Protein capture and cultural development in the Amazon Basin. American Anthropologist 77(3):526-549, 1975.

- A new approach to central brazilian social organization. M. C. Margolis \& W. E. Carter (eds.) Brazil: Anthropological Perspectives - Essays in Honor of Charles Wagley. Columbia University Press, New York, 1979: 321-342.

- Village movement in relation to resources in Amazonia. R. B. Hames \& W. V. Vickers (eds.), Adaptative Responses of Native Amazonians. Academic Press, New York, 1983: 393-449.

HANTMANN, J. L. \& S. PLOG The relationship of stylistic similarity to the patterns of material exchange. E. Ericson \& T. K. Earle (eds.), Context for Prehistoric Exchange. Academic Press, New York, 1982: 237-263.

HODDER, I. Economic and social stress and material culture patterning. American Antiquity 44(3):446454, 1979.

-. The Present Past. Batsford, Ltd, London, 1982.

LEVI-STRAUSS, C. Tristes Trópicos. Editorial Universitaria de Buenos Aires. 2' edição. [1955] 1973.

—. A noção do arcaismo em etnologia. Antropologia Estrutural I. Tempo Brasileiro, Rio de Janeiro, 1970: 117-135.

LOUKOTKA, C. Linguas indigenas do Brasil. Rev do Arquivo Municipal LIV:147-174. S. Paulo, 1939.

LOWIE, R. H. The Bororo. J. H. Steward (ed.), Handbook of South American Indians, Vol I. Smithsonian Institution. Washington, 1946: 519-520.

MARTIUS, C. Zur Ethnographie und Sprachenkunde Amerikas, zumal Brasiliens I. Friedrich Fleischer Verlag, Leipzig, 1867.

MEGGERS, B. J. Environmental limitations on the development of culture. American Anthropologist 56:801-824, 1954.

NEVES, W. A., F. M. SALZANO \& F. J. da ROCHA Principal-components analysis for Brazilian Indian anthropometric data. American Journal of Physical Anthropology 67:13-17, 1985.

NIMUENDAJÚ, C. The Apinayé. Anthropological Series 8. Catholic University of America. Washington. Anthropological Publications, Dosterhout, Netherland. [1?39] 1967.
—. The Eastern Timbira. University of California Publications in American Archaeology and Ethnology 41, Berkeley \& Los Angeles, 1946.

NOVAES, S. C. \& L. D. GRUPIONI Censo da População Bororo de 1986 (manuscrito), 1986.

MAYBURY-LEWIS, D. Akwe-Shavante Society. Clarendon Press. Oxford, 1967.

PROUS, A. Arqueologia Brasileira. Editora da UNB, Brasilia, 1992.

REGO, M. Indios de Mato Grosso. Os Bororós Coroados. Revista Brazileira, Rio de Janeiro e São Paulo, I:6-12. 1895.

RODRIGUES, A. D. I. Linguas Brasileiras. Para o Conhecimento das Linguas Indigenas. Edições Loyola, Sāo Paulo, 1986.

RONDON, C. M. da S. Relatório dós trabalhos realizados de 1900-1906 pela Comissão de Linhas Telegráficas do Estado do Mato Grosso apresentado às autoridades do Ministério da Guerra. Imprensa Nacional, Rio de Janeiro, 1949.

RONDON, C. M. S. \& FARIA, J. B. Esboço gramatical e vocabulário da língua dos indios Borôro. Conselho Nacional de Proteção aos indios 77. Rio de Janeiro, 1948.

ROOSEVELT, A. C. Chiefdoms in the Amazon and Orinoco. R. D. Drennan \& C. A. Uribe (eds.), Chiefdoms in the Americas. University Press of America, Lanham, New York, London, 1987: 153186.

ROOSEVELT, A. C. Moundbuilders of the Amazon. Geophysical Archaeology in the Marajoara Chiefdom. Academic Press, New York, 1991.

SÁ, J. B. de Relação das Povoações do Cuyabá e Mato Grosso de seos Principios thé os Prezentes Tempos. Universidade Federal de Mato Grosso e Secretaria de Educação e Cultura, Cuiabá. (Edição original: Anais da Biblioteca Nacional, Rio de Janeiro, XXIII:5-58), [1775] 1975.

SCHMITZ, P. I., I. WÜST, S. M. COPE \& U. M. E. THIES Arqueologia do Centro-Sul de Goiás. Uma fronteira de horticultores indigenas no Centro do Brasil. Pesquisas Série Antropologia 32. Instituto Anchietano de Pesquisas. São Leopoldo, 1982.

SCHULTZ, H. Informaçōes etnográficas sobre os Umotina. Revista do Museu Paulista, Universidade de São Paulo, São Paulo, XIII:75-313, 1961/62a.

SIQUEIRA, J. da C. Chronicas do Cuyabá. Revista do Instituto Histórico e Geográfico de São Paulo IV:4-217, 1898/9.

STEWARD, J. H. Handbook of South American Indians. Volume 1. Smithsonian Institution, Washington, 1946.

STEWARD, J. H. \& L. C. FARON Native Peoples of South America. MacGraw-Hill Book Company, New York, Inc., 1959.

SUSNIK, B. Los Aborignes del Paraguay I - Chaco Boreal y su Periferia (Siglus XVI y XVI). Museu Etnografico Andres Barbero. Asunción, 1978.

_. Dimensiones Migratórias y Pautas Culturales de 
WUST, I. Contribuiçōes arqueológicas, etnoarqueológicas e etno-históricas para o estudo dos grupos tribais do Brasil Central: o caso Bororo. Rev. do Museu de Arqueologia e Etnologia, S. Paulo, 2:13-26, 1992.

los Pueblos del Gran Chaco y de su Periferia. Universidad Nacional del Nordeste, Asunción, 1972.

TONELLI, A. La provenienza degli indi BororoOrientali del Mato Grosso. Estratto dagli Atti del $V$ Congresso Geografico Italiano. Milano, 1927.

TURNER, S. T. The Gê and Bororo societies as dialectical systems: a general model. D. MayburyLewis (ed.), Dialectical Societies. The Gê and Bororo of Central Brazil. Harvard University Press, Cambridge and London, 1979: 147-178.

VIERTLER, R. B. Aroe J'aro. Implicaçōes Adaptativas das Crenças e Práticas Funerárias dos Bororo do Brasil Central. Tese de Livre Docência. Universidade de São Paulo. São Paulo (não publicado), 1982.

—. A formação da sociedade Bororo: mitologia e consideraçōes etno-históricas. Revista de Antropologia, Universidade de São Paulo, São Paulo, $X X I X: 1-39,1986$.

—. Mito, rito e condiçōes de sobrevivência entre os indios Bororo do Mato Grosso: Esboço para uma abordagem interdisciplinar do fenômeno mítico. Revista do Instituto de Estudos Brasileiros, São Paulo, 27:113-124, 1987.

—. O estudo antropológico de aldeias indígenas no Brasil: Estudo atual de uma pesquisa entre os Bororo. Dédalo, Revista do Museu de Arqueologia e Etnologia, Universidade de São Paulo, São Paulo, 27:47-64, 1989.

—. A Refeição das Almas. Hucitec - Edusp, Editora da Universidade de São Paulo, São Paulo, 1991.

WÜST, I. Continuidade e Mudança - Para uma Interpretação dos grupos ceramistas pré-coloniais da Bacia do Rio Vermelho, Mato Grosso. Tese de Doutorado, Universidade de São Paulo - FFLCH (não publicado), 1990.

ZERRIES, O. The bull roarer among South American Indians. Revista do Museu Paulista, Universidade de São Paulo, São Paulo, VII:275-304, 1953.

—. Organização dual e imagem do mundo entre índios brasileiros. E. Schaden, Leituras de Etnologia Brasileira. Companhia Editora Nacional. São Paulo, 1976: 107-126. 